19 Revue d'histoire du XIXe siècle

Société d'histoire de la révolution de 1848 et des

révolutions du XIXe siècle

39 | 2009

Le monde de l'imprimé: des territoires aux acteurs -

Education et politique - Histoires politiques

Jamie L. BRONSTEIN, Caught in the Machinery. Workplace Accidents and Injured Workers in Nineteenth-Century Britain

Stanford, Stanford University Press, 2008, 222 p. ISBN : 0-8047-0008-7.

55 dollars.

François Jarrige

\title{
OpenEdition
}

Journals

Édition électronique

URL : http://journals.openedition.org/rh19/3974

DOI : 10.4000/rh19.3974

ISSN : $1777-5329$

Éditeur

La Société de 1848

Édition imprimée

Date de publication : 10 décembre 2009

Pagination : 190-192

ISSN : 1265-1354

Référence électronique

François Jarrige, " Jamie L. BRONSTEIN, Caught in the Machinery. Workplace Accidents and Injured Workers in Nineteenth-Century Britain », Revue d'histoire du XIXe siècle [En ligne], 39 | 2009, mis en ligne le 26 mars 2010, consulté le 22 septembre 2020. URL : http://journals.openedition.org/rh19/3974 ; DOI : https://doi.org/10.4000/rh19.3974

Ce document a été généré automatiquement le 22 septembre 2020.

Tous droits réservés 


\section{Jamie L. BRONSTEIN, Caught in the Machinery. Workplace Accidents and Injured Workers in Nineteenth-Century Britain}

Stanford, Stanford University Press, 2008, 222 p. ISBN : 0-8047-0008-7. 55 dollars.

François Jarrige

1 Dans le monde du travail du XIX siècle les accidents étaient fréquents et particulièrement violents. Les récits de bras arrachés et de corps déchiquetés sont familiers à ceux qui s'intéressent au travail ou à la presse friande de ces faits divers. L'historiographie s'est penchée depuis longtemps sur ces accidents du travail pour en recenser le nombre ou pour saisir leurs significations sur l'expérience de la condition ouvrière. Dans cette étude, Jamie L. Bronstein propose une histoire culturelle des accidents du travail et de leur signification socio-politique dans le monde transatlantique - États-Unis et Grande-Bretagne. Elle y montre comment, en GrandeBretagne comme aux États-Unis, l'idéal du travailleur libre (the free labor ideal) a contribué à retarder l'avènement d'une législation protectrice pour les ouvriers. À travers une démonstration essentiellement chronologique et comparatiste elle explique comment, entre le début du XIX ${ }^{e}$ siècle et les années 1880 , l'accident a été profondément requalifié : d'une tragédie individuelle il est devenu peu à peu un problème social nécessitant l'intervention de l'État.

2 L'espace de travail du XIXe siècle était plein de périls. Grâce au développement massif de la presse et aux nombreux rapports officiels, nous connaissons mieux les dangers associés au travail au XIX ${ }^{\mathrm{e}}$ siècle que ceux des périodes antérieures. Les historiens qui se sont intéressés à ce phénomène ont eu tendance à concentrer le regard sur les industries où les catastrophes étaient les plus spectaculaires comme la construction ferroviaire ou l'industrie minière, mais on sait également que les accidents étaient fréquents dans l'industrie textile comme dans la plupart des secteurs d'activité. Aucun 
métier n'était à l'abri des dangers associés aux nouveaux procédés de production, alors que les bouleversements industriels multipliaient les risques. L'inspecteur des usines Léonard Horner, qui sera un ardent porte-parole des intérêts des travailleurs, recense en 1859 quelques 1097 accidents causés par des machines en Angleterre. Face à ces menaces, les travailleurs étaient souvent démunis et se retrouvaient sans secours. Avant les lois sur l'indemnisation des travailleurs et sur la responsabilité patronale de 1880 , les ouvriers devaient aller en justice pour obtenir des secours. Mais face à la longueur et la difficulté de cette procédure, les travailleurs préféraient recourir à d'autres voies pour obtenir des aides: la philanthropie patronale, la charité des consommateurs et du public, ou encore la solidarité familiale et professionnelle.

L'une des forces de l'étude de Jamie L. Bronstein réside dans le fait qu'elle n'en reste pas à la seule analyse misérabiliste des accidents, de la fragilité des travailleurs et de leur manque de protection, mais qu'elle tente aussi une histoire culturelle des différentes modalités d'interprétation de ces accidents. C'est en examinant les significations culturelles et les représentations des accidents qu'on pourra comprendre pourquoi l'indemnisation des ouvriers fut si lente à se mettre en place, alors que s'impose, par exemple, plus tôt les régulations du temps de travail. La sécurité au travail n'était pas une revendication centrale de la main-d'œuvre. À partir de l'étude des récits d'accidents dans la presse, l'auteure suggère que cela s'explique par le fatalisme qui domine les représentations: l'accident est soit le produit du destin, l'ouvrier est victime de la Providence ou de sa propre imprudence, soit un sacrifice nécessaire et inévitable sur l'autel du progrès.

4 Dans l'univers juridique anglo-américain de la première moitié du XIX ${ }^{e}$ siècle, le respect pour les lois du marché et le refus de toute intervention pour réguler l'industrie constituait par ailleurs une forte résistance à toute velléité d'intervention du gouvernement. L'intervention d'une manière ou d'une autre dans le contrat qui lie les employeurs et les ouvriers risquait de pervertir le système économique et donc la richesse de la nation. Mais le travailleur pensé comme un agent libre et autonome ne subsume pas l'ensemble de la main-d'œuvre, les enfants, les femmes et les esclaves n'étaient pas des agents libres, ils ne sauraient donc être tenus pour responsables de leur sort. C'est finalement dans les années 1870 que la question de l'intervention de l'État s'affirme comme une nécessité en Grande-Bretagne, bien avant que l'idée ne s'impose aux États-Unis.

5 Comment expliquer cette différence ? Dans l'épilogue, l'auteur suggère quelques pistes qui mériteraient d'être creusées. Aux États-Unis, la technologie devient par exemple l'un des fondements de l'indépendance nationale et la critique de ses effets sur la maind'œuvre peine à s'imposer. La plus grande décentralisation des États nord-américains créaient par ailleurs de nombreux obstacles à l'adoption d'une législation protectrice alors qu'en Grande-Bretagne les réformes ne devaient passer que par un seul forum. Alors qu'en Grande-Bretagne la multiplication des théories de l'exploitation ouvrière met à mal le discours de l'agent libre selon lequel c'est au travailleur de faire face aux vicissitudes du marché du travail par sa propre prévoyance, aux États-Unis l'afflux continu de nouveaux immigrants aurait au contraire renforcé l'idée selon laquelle la main-d'œuvre était composée de nombreux « agents libres».

6 Cet ouvrage ouvre en définitive de nombreuses pistes pour développer ce qui pourrait être une histoire sociale et culturelle de l'accident à l'âge industriel. Les dernières décennies ont connu de nombreux renouvellements de la question de la violence et de 
la guerre, mais assez peu d'études se sont intéressées aux violences au quotidien dans l'espace de travail, même si la question des maladies professionnelles et de la santé au travail entre de plus en plus dans l'agenda des historiens ${ }^{1}$. L'ouvrage de Jamie L. Bronstein contribue aussi à historiciser la genèse de la confiance dans l'industrie et la technique qui naît au XIX siècle, consensus qui se fissure aujourd'hui alors que la question des risques industriels resurgit avec force dans l'espace public. 